\title{
Trends in Daily Temperature and Precipitation Extremes over Dire-Dawa, 1980-2018
}

\author{
Gezahegn Bekele Tashebo* Elias Fiseha Mekonn Aklile Assefa Eshete \\ Meteorological Research \& Studies P.O.Box 1090
}

\begin{abstract}
Extreme climate events have profound impacts on economies and livelihoods of many regions of the world. In Ethiopia, for example the major floods such as in Dire-dawa and Omo basin of June 2006 illustrates the risks to ecosystems, human health and welfare, and infrastructure from short duration weather extremes. There is a paucity of information on trends in climate extremes in the country. However, a joint World Meteorological Commission for Climatology/World Climate Research Programme (WCPRP) project on climate Variability and Predictability (WMO CCl/CLIVAR) Expert Team (ET) on Climate Change Detection, Monitoring and Indices have defined 27 core climate indices mainly focusing on extreme events which can be derived through the use of RClim-Dex Software. In this study, therefore, the RClim-Dex software has been used to derive climate extreme indices for Dire-Dawa station in the Eastern Ethiopia region based on climate data for the period 1980 to 2018. The objective was to examine changes in climate extremes over the city for water provision and urban planning such as flood management practice. These indices have shown insignificant decreasing trends in annual rainfall, Consecutive maximum 5 days precipitation and R95p, R95p\% precipitation. A Significant warming pattern was evident in both the maximum and minimum temperature indices. In general the results of this study are in a general agreement with what we have been observed with people's perception about extreme weather events in the last 39 years.
\end{abstract}

Keywords: RClimDex, Climate Change, extremes Weather, trends and people perception

DOI: $10.7176 / \mathrm{JEES} / 11-9-03$

Publication date:September $30^{\text {th }} 2021$

\section{INTRODUCTION}

Climate change and especially extreme climatic events in recent years have been increasingly expressed as described by Solomon et al. (2007), these events can greatly affect the nature and the living world, and the consequences will be felt in the economic, environmental and social spheres. In order to precisely implement the risk assessment of climate change, the World Meteorological Organization (WMO) and the United Nations Environment Programme (UNEP) established a special body called the Intergovernmental Panel on Climate Change (IPCC). The Report of the Working Group on Climate Change Detection and Related Rapporteurs recommends that extreme climate indices need to be used for the detection and monitoring of extreme climatic events (Peterson et al., 2001).

Ethiopia is one of the countries whose economy is highly dependent on rain-fed agriculture and also facing recurring cycles of flood and drought. Current climate variability is already imposing a significant challenge to Ethiopia in general and Dire-Dawa in particular, by affecting food security, water and energy supply, poverty reduction and sustainable development efforts, as well as by causing natural resource degradation and natural disasters. Metrologically, Dire-Dawa Administration is characterized by an arid and semi-arid climate, thus, receives low and erratic rainfall (Bekele, 1997). Prolonged droughts time and again affected the rural part of Dire Dawa.

This paper contains an analysis of eleven climate indices for Dire-Dawa City in the period from 1980 to 2018. The indices that were analyzed are the following: summer days (SU), hot day frequency (TX90p), hot night frequency (TN90p), Monthly lowest minimum temperature (TNn) coolest night, cool day frequency (TX10p), cool night frequency (TN10p), Monthly minimum value of daily max temperature (TXn), annual total wet-day precipitation (prcptot), 5-day precipitation (R5day) and very wet day precipitation (R95p).

\section{STUDY AREAS AND DATA COLLECTION}

In this study, Dire-Dawa city in Ethiopia were selected for analyzing the extreme climate indices. Because it is the most vulnerable city by extreme climate events like drought, flash flood high and temperature. It is located in the eastern part of the country enclosed by the state of Somalia and the state of Oromia. Dire is found at the distance of 346.61Kilometers from the capital City Addis Ababa. The administration has estimated area 128,802 hectares. The climate type is characterized by extremely variable temperature conditions, the annual average for the year in Dire-dawa is $76.0^{\circ} \mathrm{F}\left(24.4^{\circ} \mathrm{C}\right)$, with an annual average rainfall of $24.2^{\prime \prime}(614.7 \mathrm{~mm})$.Dire-dawa is situated at the $9.9667^{\circ}$ latitude north and $41.580^{\circ}$ longitude east, and at an altitude of 1,276 m. Daily values of maximum (Tmax) and minimum (Tmin) air temperature and precipitation is collected from Dire -Dawa station. And a structured questionnaire was prepared, distributed and assessed their perception of community with 90 selected people who live in Dire-dawa over 30 year. The interview included information on perceptions of the respondent about trends 
of extreme weathers, climate conditioning over the past 3 decade, severity of the change in vulnerable communities and major constraints that hindering copy mechanism.

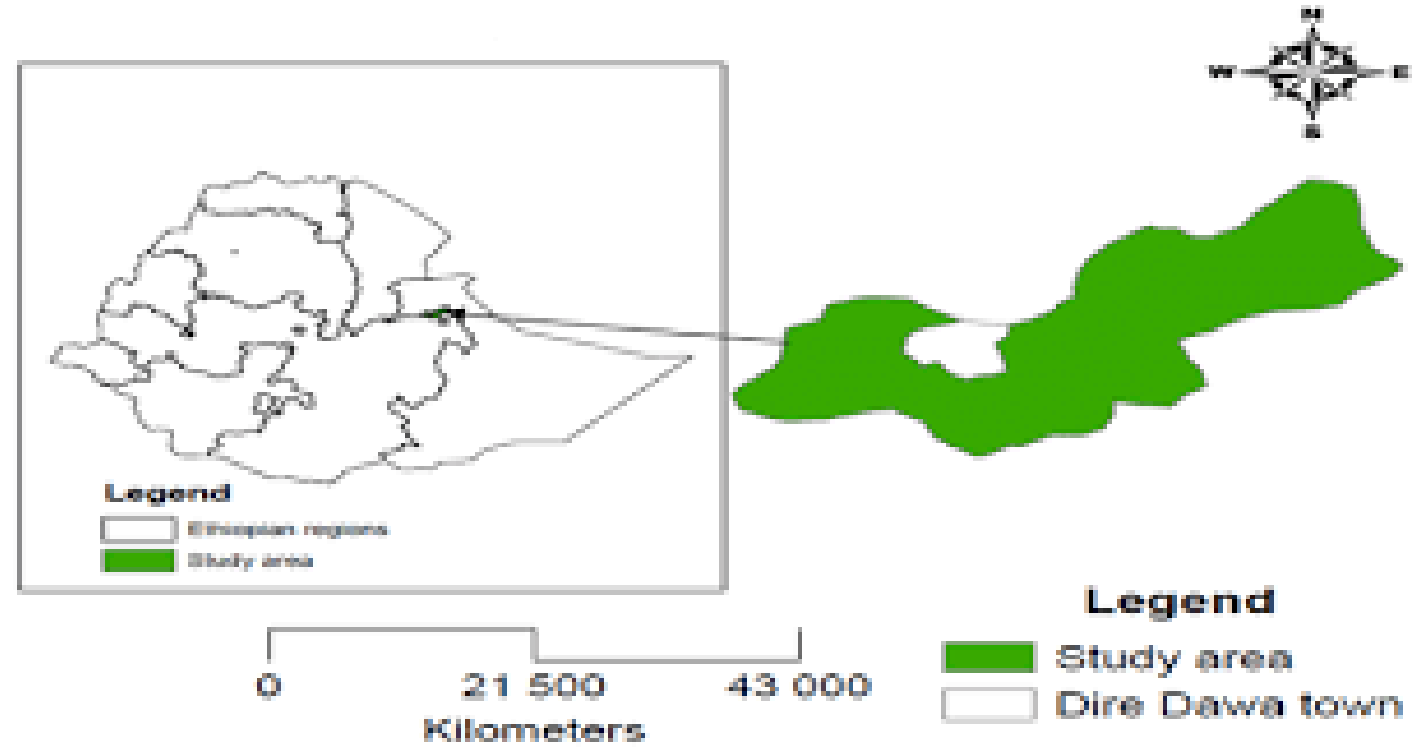

Figure 1 Location of study area

\section{DATA AND METHODOLOGY}

Daily maximum and minimum surface air temperatures and daily precipitation data for Dire-Dawa meteorological station were taken from National Meteorological Agency. On the basis of recommendations given by the ETCCDMI (Expert Team on Climate Change Detection, Monitoring and Indices), a calculation of ten extreme climate indices was performed

In this study a rigid data quality control have been applied, because indices of extremes are sensitive to changes in station exposure, equipment, and observer practice (Haylock et al., 2006). Data Quality Control (QC) is a prerequisite for determining climatic indices. The quality control performs the following steps:

Replaces all missing values (currently coded as -99.9) into an internal format that the software recognizes (i.e. NA, not available), and

Replaces all unreasonable values into NA. Those values include: a) daily precipitation amounts less than zero, and; b) daily maximum temperature less than daily minimum temperature. In addition, QC also identifies outliers in daily maximum and minimum temperature and the resulting time series is compared with people perception mapping.

\section{Climate Extreme Indices and Analytical Methods}

The 27 ETCCDI indices agreed by the international community aim to monitor changes in "moderate" extremes and to enhance studies on climate extremes using indices that are statistically strong and cover large range of climates and have a great signal-to-noise ratio (Min et al., 2011). The indices are calculated from daily precipitation data (Petersonet al., 2002; Karl and Easterling, 1999). From the core extreme indices, 3 extreme precipitation indices and 7 extreme temperature indices were selected for the present study (Table 1). All trends for indices chosen were calculated annually using the Software RClimDex 3.5.3

Percentile indices were calculated using the standard reference period 1981 to 2010 to make results easily comparable with other studies using the same reference period. 
Table 1 list of ten core ETCCDI indices that we have used for this study (that are better explain the climate behavior of the study area

\begin{tabular}{|l|l|l|l|}
\hline ID & Name & Definition & Units \\
\hline SU & Summer Days (hot days) & Annual count when TX(daily maximum) $>=25^{\circ} \mathrm{C}$ & Days \\
\hline TNn & Min TN (coolest night) & Monthly lowest TN & ${ }^{\circ} \mathrm{C}$ \\
\hline TXn & Min Tx(coolest day) & Monthly lowest TX & ${ }^{\circ} \mathrm{C}$ \\
\hline PRCPTOT & $\begin{array}{l}\text { Annual total wet-day } \\
\text { precipitation }\end{array}$ & $\begin{array}{l}\text { Annual total precipitation in wet days (daily } \\
\text { precipitation } \geq 1 \mathrm{~mm})\end{array}$ & $\mathrm{mm}$ \\
\hline R95p & Very wet day precipitation & $\begin{array}{l}\text { Annual total precipitation when RR }>95^{\text {th }} \\
\text { percentile of } 1981-2010 \text { daily rainfall }\end{array}$ & $\mathrm{mm}$ \\
\hline RX5day & 5-day precipitation & Consecutive maximum 5 days precipitation & Days \\
\hline TX10p & Cool day frequency & $\begin{array}{l}\text { Percentage of days when TX }<10^{\text {th }} \text { percentile of } \\
1981-2010\end{array}$ & $\%$ \\
\hline TN10p & Cool night frequency & $\begin{array}{l}\text { Percentage of days when TN }<10^{\text {th }} \text { percentile of } \\
1981-2010\end{array}$ & $\%$ \\
\hline TX90p & Hot day frequency & $\begin{array}{l}\text { Percentage of days when TX }>90^{\text {th }} \text { percentile of } \\
1981-2010\end{array}$ & $\%$ \\
\hline TN90p & Hot night frequency & $\begin{array}{l}\text { Percentage of days when TN }>90^{\text {th }} \text { percentile of } \\
1981-2010\end{array}$ & $\%$ \\
\hline
\end{tabular}

\section{RESULT AND DISCUSSIONS}

\section{Hot extremes (SU25, TNn, TX90p and TN90p)}

Figure below depicted that, the long term SU25, TX90p and TN90 percentiles have been increasing at magnitudes of $0.2,0.846$ and 0.038 during the past 39 years.
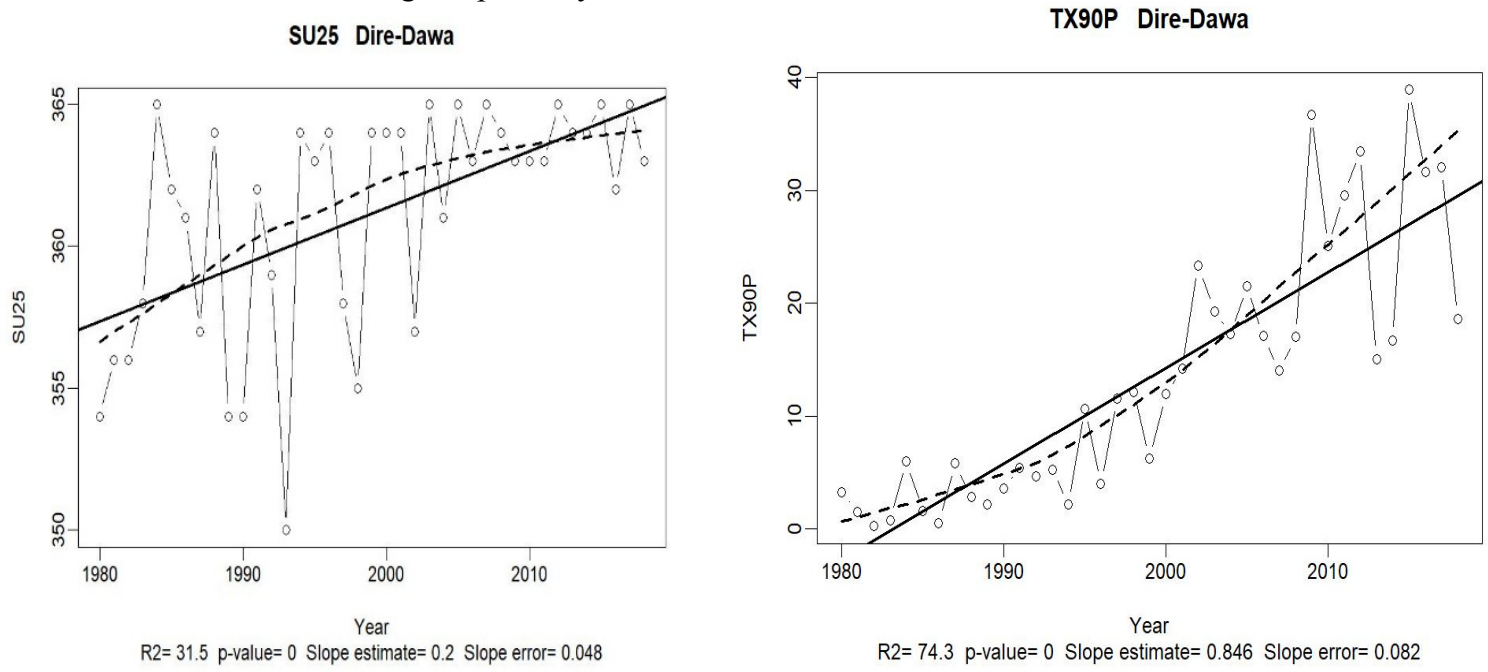

Figure 2 Annual count when TX (daily maximum) $>=25^{\circ} \mathrm{C}$ Figure 3 Percentage of days when TX $>90^{\text {th }}$ percentile of 1981-2010

TN90P Dire-Dawa

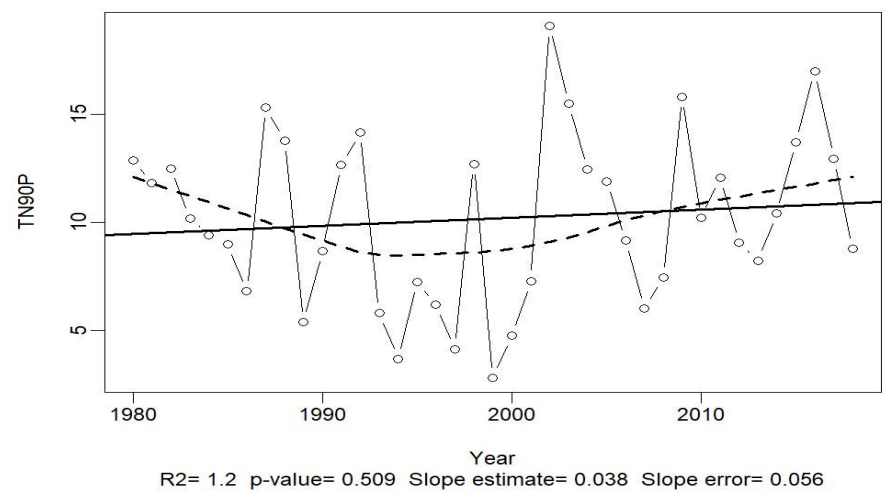

Figure 4 Percentage of days when TN $>90^{\text {th }}$ percentile of $1981-2010$ 


\section{Cold extremes (TX10p, TXn, TNn and TN10p)}

Two of the cold indices cool day frequency (TX10p) and cool night (TNn) are a consistent with cooling of several significant trends. Contrary to what cool night frequency (TN10p) and coolest day (TXn) indicates in increasing trends.
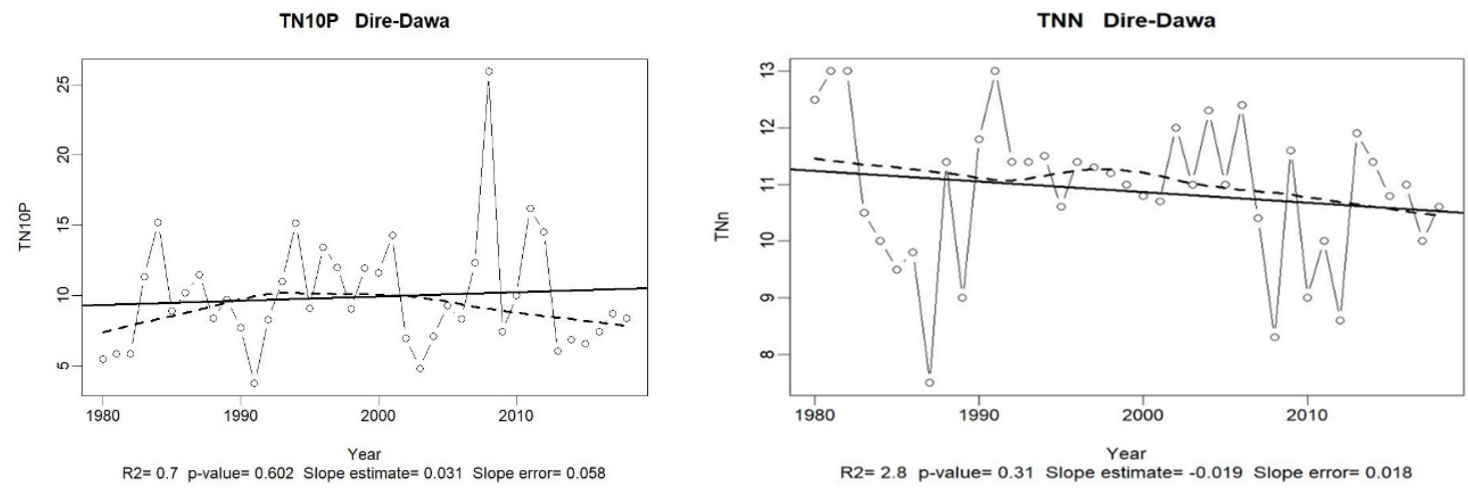

Figure 5 Percentage of days when TN $<10^{\text {th }}$ percentile of 1981-2010 Figure 6 Monthly lowest TN
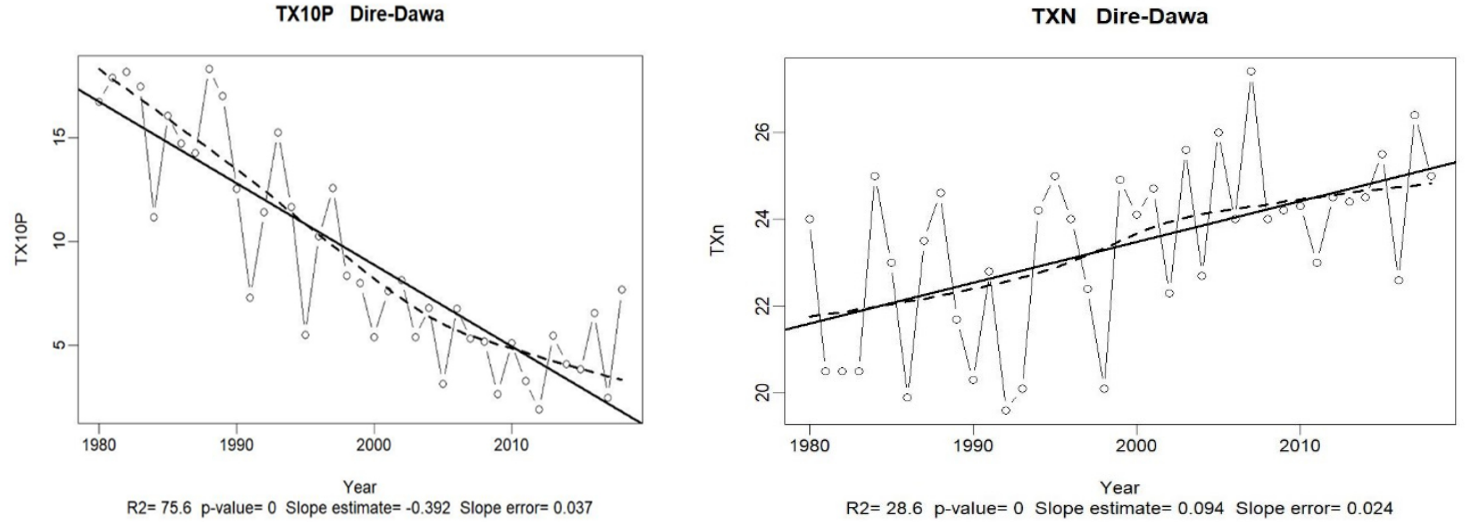

Figure 7 Percentage of days when TX $<10^{\text {th }}$ percentile of $1981-2010$

Figure 8 Monthly lowest TX

\section{Precipitation extremes (PRCPTOT, R5dayand R95p)}

Figure below illustrates the total annual precipitation and the trend line of Dire City. The trend of PRCPTOT shows a steady increase in precipitation from 1980 to 1995 and decreased 1995 to 2005. Again it also shows an increasing trend at a lower magnitude. The greatest amount of precipitation was in 2010 and it was $\sim 950 \mathrm{~mm}$, while the smallest was $\sim 200.0 \mathrm{~mm}$ and it was recorded in 2015.It is also a negative Dire-City-averaged trend was detected for maximum 5-day precipitation (R5day) and $95^{\text {th }}$ percentile from the base period. In general the signs of the trends of precipitation indice indicate decreasing trend at a rate of $-1.626,-0.549$ and $-0.64 \mathrm{~mm}$ per decade respectively

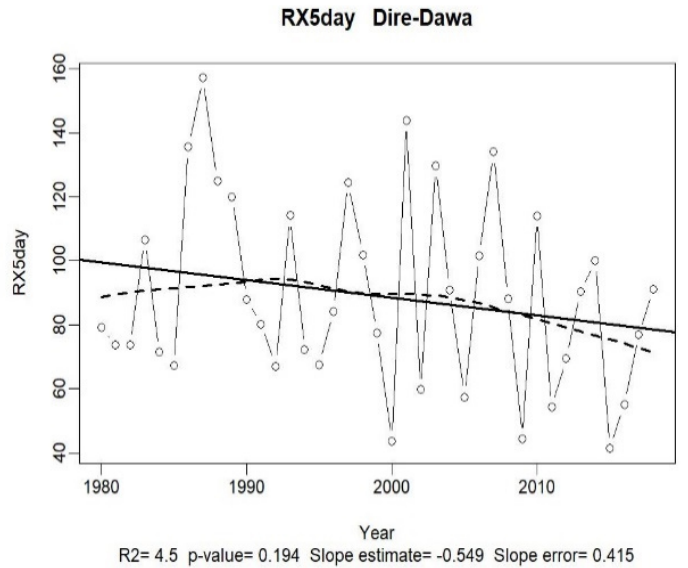

Figure 9 Consecutive maximum 5 days precipitation

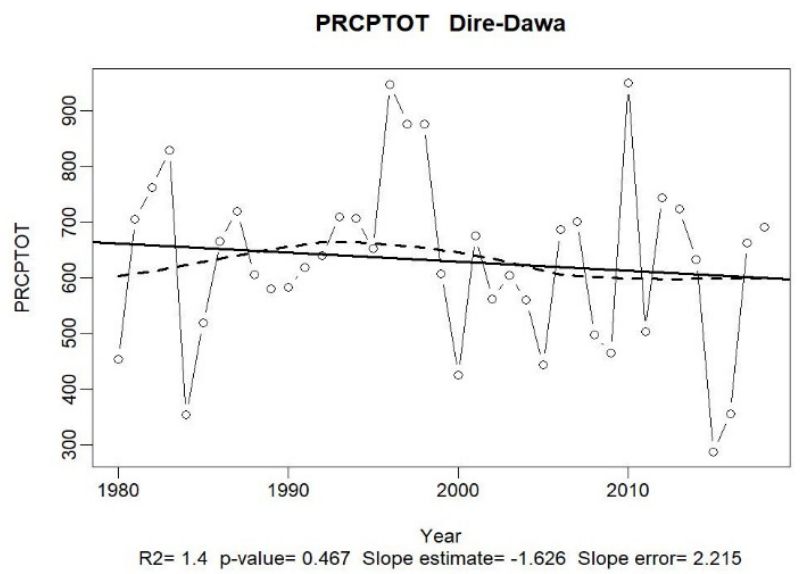

Figure 10 Annual total precipitation in wet days (daily precipitation $\geq 1 \mathrm{~mm}$ 


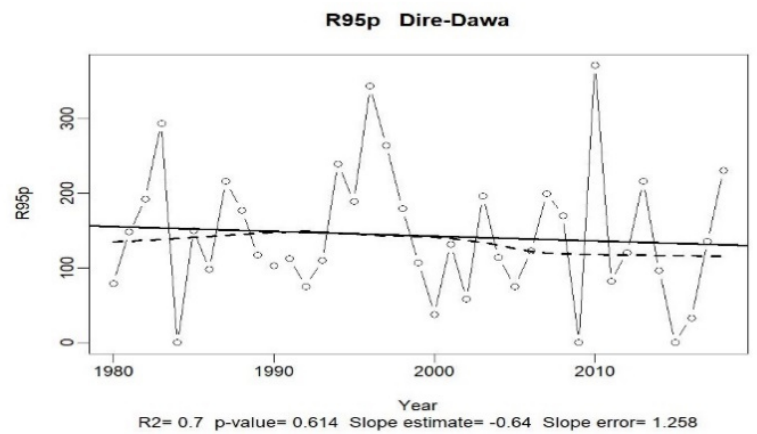

Figure 11 Annual total precipitation when $R R>95^{\text {th }}$ percentile of $1981-2010$

Table 2 Annual trends of the extreme indices of daily temperature and precipitation for Dire-Dawa station

\begin{tabular}{|c|c|c|c|c|c|}
\hline Indices & Slope & $\mathbf{R}^{\mathbf{2}}$ & $\mathbf{P}$ & Increase/Decrease & Significance \\
\hline SU & 0.2 & 31.5 & 0 & Increase & Highly significant \\
\hline TXn & 0.094 & 28.6 & 0 & Increase & Highly significant \\
\hline TNn & -0.019 & 2.8 & 0.31 & Decrease & Not significant \\
\hline prcptot & -1.626 & 1.4 & 0.467 & Decrease & Not signnificant \\
\hline RX5day & -0.549 & 4.5 & 0.467 & Decrease & Not significant \\
\hline R95p & -0.64 & 0.7 & 0.614 & Decrease & Highly significant \\
\hline TX10p & -0.392 & 75.6 & 0 & Decrease & Highly significant \\
\hline TN10p & 0.031 & 0.7 & 0.602 & Increase & Not significant \\
\hline TX90p & 0.846 & 74.3 & 0 & Increase & \\
\hline TN90p & 0.038 & 1.2 & 0.509 & Increase & \\
\hline
\end{tabular}

\section{PERCEPTION OF CHANGES IN EXTREME WEATHER EVENTS}

People's perception of long-term trends in extreme weather in the area noticeably appears to strongly correspond with actual evidence of the amounts of weather recorded at Dire-Dawa Meteorological stations. Nearly 95 percent of the interviewed community responded that local extreme rainfalls have decreased in the last several decades and increased temperature extremes.

Characteristics of the study population: Average age of male and female respondents was 39 and 32 years respectively about $80 \%$ of the respondents have ever been to school, and $42 \%$ had secondary education or above.

\section{People's Knowledge of Climate Change}

\section{Understanding Climate Change: It's meaning and Causes}

Most of the surveyed people have heard about the term "climate change". And they are familiar with the concept of climate change. About $88 \%$ they say have heard of it while $9 \%$ say they have never heard of it or 3\% "don't know"

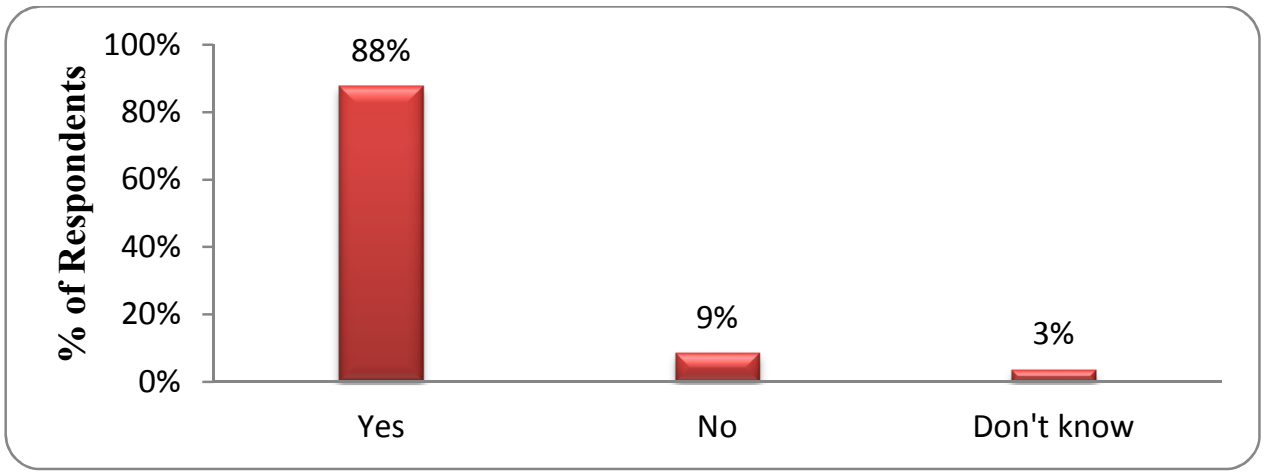

Figure 12 Respondents were asked: Have you heard about climate change?

Climate conditions over the past 3 decades

After mentioning climate change, we asked respondents about changes in the weather and climate in their City over the past three decades. A majority (91\%) of they say that Temperature increased, $(8 \%)$ no change and only about $1 \%$ they say decreased. 


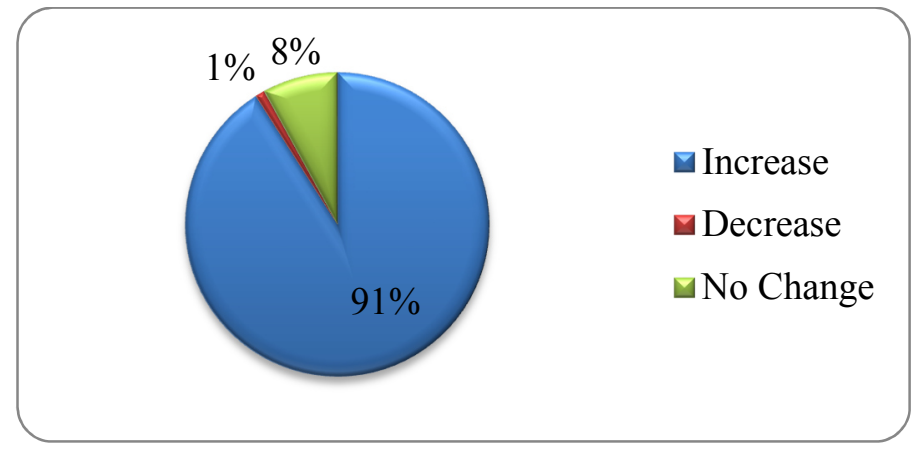

Figure 12.0

Figure 13 Temperature conditions over the past 3 decades

When they asked what the cause of climate Change is, the respondents gave varied responses. deforestation, increase industrialization, urbanization, increase $\mathrm{CO} 2$ emission from vehicles, increase population, over lead an appropriate urbanization, global warming, green house rise increase to Atmospheric CO2, increasing people who are smoking cigarettes, the governments don't control industries.

Severity of the Change in Vulnerability As we have indicated the above question most of the respondents said that they had observed climate change in the last-30 years. Regarding intensity, $51 \%$ of the respondents believed that the impact was "a great deal" (Figure 3.0). This perception was stronger in flash flood and drought.

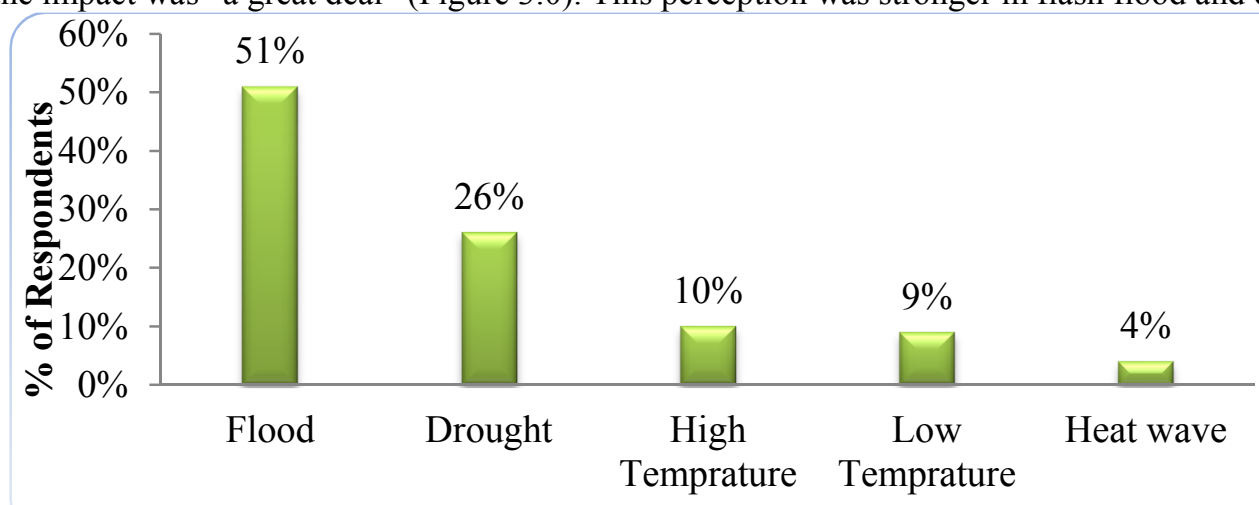

Figure 14 Opinions on impact of climate change in the study areas

Major constraints that hindering copy mechanisms

The graph below indicates some of the main challenges those hindering copy mechanisms.

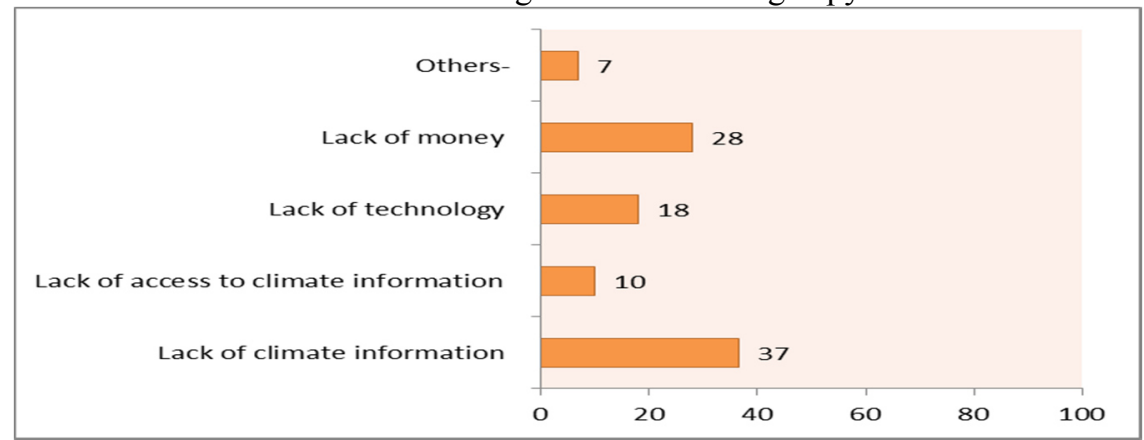

Figure 15 main challenges hindering copy mechanisms

\section{CONCLUSIONS}

This study presents an evaluation of extreme weather events as a result of climate change in study area by focusing on the analysis of daily precipitation, minimum, maximum temperature and perception of people on extreme weather events. The observed features are very important in the context of global warming trends observed during the late $20^{\text {th }}$ and $21^{\text {st }}$ century. The result shows a positive significant increasing of temperature pattern and insignificant decreasing rainfall indices. This trend suggests that the city exhibited warming trends. In general the results of this study are in a general agreement with what we have been observed with people's perception about extreme weather events in the last 39 years.

The information is important as it tells that the climate extremes can be a factor which may contribute to the 
limitations in the ability of society and the area's fragile environment to cope with climate extremes. Water provision and urban planning practice in these areas would therefore require careful and full mainstreaming of this information at all stages of decision making.

\section{REFERENCE}

1. Beyene AN (2016) Precipitation and Temperature Trend Analysis in Mekelle city, NorthernEthiopia, the Case of Illala Meteorological Station.

2. De Melo, T.M.,Louzada, J.A.S. and Pedrollo, O.C. (2015) Trends in Extreme Indices andseasonal Analysis of Precipitation and Temperature in the Northwest Region of Rio Grande do Sul, Brazil. American Journal of Climate Change, 4, 187-202

3. Ethiopia: National adaptation programme of action - NAPA (2007)

4. Marigi, S.N., Njogu, A.K. and Githungo, W.N. (2016) Trends of Extreme Temperature and rainfall Indices for Arid and Semi-Arid Lands of South Eastern Kenya. Journal of Geoscience and Environment Protection, 4, 158-171.

5. National meteorological services agency of Ethiopia, Climate and agro climatic resources of Ethiopia, Vol.1, Agues 1985.

6. Tesfaye, H., 1986. Climatic variability and support feedback mechanism in relation to the Sahelo-Ethiopian droughts. M.Sc. Thesis, Department of Meteorology, University of Reading, U.K. pp.119-137.

7. WIREs Climate Change 2011. doi: 10.1002/wcc. 147

8. 2007 population and housing. Census of. Ethiopia. Administrative. Report. Central Statistical.Authority. April 2012. Addis Ababa.

9.https://www.ipcc.ch/pdf/assessment-report/ar5/wg2/WGIIAR5-Chap22_FINAL.pdf http://dx.doi.org/10.4236/gep.2016.412012

10. World bank, Addis Ababa - Enhancing Urban Resilience: city strength resilient cities Program, working paper 100980, Washington D.C, 2015.

11. S. Eriksen, K. O'Brien, L. Rosentrater, Climate Change in Eastern and Southern AfricaImpacts, Vulnerability and Adaptation, GECHS Report, ISSN 1504-6338, Oslo, 2 (2008) 1-27.18

12. Kelemen A., Munch W., Poelman H., Gakova Z., Dijkstra L., TorighelliB ., 2009 Regions 2020 - the climate change challenge for European Regions, European Commission, directorate General for Regional Policy, Background document to Commission Staff Working Document, An assessment of future challenges for EU Regions, $27 \mathrm{pp}$.

13. Piticar A., Ristoiu D., 2012 Analysis of air temperature evolution in Northeastern Romaniaand evidence of warming trend. Carpathian Journal of Earth and Environmental Sciences7(4):97-106.

14. Piticar A., Ristoiu D., 2014 [The influence of changes in teleconnection pattern trends on temperature and precipitation trends in Northeastern Romania]. Risks and DISASTERSXIII, 14(1):109-122 [in Romanian].

15. Zhang, X., Alexander, L., Hegerl, G.C., Jones, P., Tank, A.K., Peterson, T.C., Trewin, B. and Zwiers, F.W., 2011. Indices for monitoring changes in extremes based on daily 